\section{Infant mortality in a very low birth weight cohort from a public hospital in Rio de Janeiro, RJ, Brazil}

\section{Mortalidade infantil em coorte de muito baixo peso ao nascer de um hospital público no Rio de Janeiro, RJ, Brasil}

Regina Coeli Azeredo Cardoso 1

Patrícia Viana Guimarães Flores 2

Cláudia Lima Vieira 3

Kátia Vergetti Bloch 4

Rejane Sobrino Pinheiro 5

Sandra Costa Fonseca 6

Claudia Medina Coeli 7

1-5,7 Instituto de Estudos em Saúde Coletiva. Universidade Federal do Rio de Janeiro. Praça Jorge Machado Moreira. Ilha do Fundão. Cidade Universitária. Rio de Janeiro, RJ, Brasil. CEP: 21.944-970.

E-mail: pguimflores@gmail.com

6 Instituto de Saúde da Comunidade. Universidade Federal Fluminense. Rio de Janeiro, RJ, Brasil.

\section{Resumo}

Objetivos: avaliar a mortalidade infantil em recém-nascidos de muito baixo peso ao nascer em um hospital público no município do Rio de Janeiro, Brasil (2002-2006).

Métodos: foi realizado um estudo de coorte retrospectivo utilizando o método probabilístico de linkage para identificar a mortalidade infantil. As proporções de mortalidade infantil foram calculadas de acordo com os intervalos de peso ao nascer e periodo de óbito. Kaplan-Meier foi utilizado para estimar a sobrevida. A associação entre escolaridade materna e sobrevida dos recém-nascidos de muito baixo peso foi avaliada por modelos de Cox ajustados para: cuidado pré-natal, peso ao nascer e idade gestacional.

Resultados: no estudo havia 782 recém-nascidos de muito baixo peso. Destes, 28,6\% morreram antes de completar um ano. A mortalidade neonatal foi de $19,5 \%$ e a mortalidade neonatal precoce $14,9 \%$. A mortalidade foi maior no grupo de menor peso (71,6\%). Recém-nascidos de mães com menos de quatro anos de estudo tiveram risco 2,5 maior de morte em comparação com aqueles com mães com mais de oito anos de estudo, mesmo após ajuste para fatores mediadores.

Conclusões: os resultados encontrados mostraram maior mortalidade entre crianças de muito baixo peso ao nascer. Baixa escolaridade foi um fator preditor independente de mortalidade infantil nesta população de baixa renda..

Palavras-chave Mortalidade infantil, Muito baixo peso ao nascer, Estudos de coortes, Modelos probabilísticos, Sistemas de Informação em Saúde 


\section{Introduction}

Preterm birth, defined as birth before 37 weeks of gestational age, is associated with increased risk of death in the first year of life, even for borderline preterm infants (born at gestational age of 32 to 36 weeks), and birth weight appears to be one of the main predictive factors for neonatal and postneonatal survival. The term low birth weight (LBW) is used to describe newborns with birth weight less than $2500 \mathrm{~g}$. LBW is further categorized as moderately low birth weight (MLBW: $1500-2499$ g), very low birth weight (VLBW: $<1500 \mathrm{~g}$ ), and extremely low birth weight (ELBW: $<1000 \mathrm{~g}$ ).

In the United States, infant mortality failed to show a decline from 2001 to 2005 . This plateau is partially due to the increase in preterm and very low birth weight deliveries. ${ }^{1}$ According to Kramer et al., 2 possible causes of the increase in preterm births include the growing proportion of older mothers, adverse socioeconomic conditions, risk behavior during pregnancy, and new assisted reproduction techniques. According to the National Center for Health Statistics (NCHS), 55\% of infant deaths (in those less than one year of age) in the United States occur in children born at a gestational age of less than 32 weeks, who represent only $2 \%$ of all births. ${ }^{1}$

In Brazil, 35,000 infants weighing less than 1500 $\mathrm{g}$ are born per year, representing $1.2 \%$ of all births, but accounting for $43 \%$ of infant mortality in the country. ${ }^{3}$ Brazilian studies evaluating birth cohorts suggest that increases in preterm deliveries may be contributing to the slower reduction in neonatal mortality in the country in recent years. ${ }^{4}$ However, in Brazil, assisted reproduction accounts for only a small proportion of preterm births. Other factors such as pre-gestational maternal diseases, hypertensive disease in pregnancy, low maternal schooling, and illicit drug use probably contribute more to preterm births. 5

Low birth weight can result from early birth, intrauterine growth restriction, or both. Adverse socioeconomic conditions lead to a series of intermediate factors that favor preterm birth, low birth weight, and higher mortality. Pregnancy at an early age, alcohol and drug consumption, smoking, stress, multiparity, short birth spacing, nutritional deficiencies, inadequate gestational weight gain, and inadequate prenatal care are some examples of factors that act as mediators in the causal pathway that relates low socioeconomic status to preterm birth, low birth weight, and perinatal and infant mortality. ${ }^{6}$ A study in Rio de Janeiro (Brazil) 6 evaluated socioeconomic inequalities in relation to low birth weight and peri- natal mortality and found major inequalities in schooling, with the worst results for illiterate mothers or those with four years of primary schooling or less. A Canadian study showed that the effects of maternal schooling on perinatal outcomes (preterm birth and low weight for gestational age) were more favorable and independent of income (considering both the individual and community levels). ${ }^{7}$ Specifically related to very low birth weight infants, some studies have shown the importance of socioeconomic factors, especially employment status and schooling. $6-7$

Few studies have evaluated mortality in the first year of life in cohorts of very low birth weight infants in low-income populations. The aim of this study was to evaluate infant mortality (in those under one year-old) in a very low birth weight (VLBW) cohort, according to maternal, pregnancy, delivery and neonatal characteristics.

\section{Methods}

A non-concurrent cohort study was conducted, using probabilistic record linkage for the identification of deaths up to one year of life in a very low birth weight cohort from a public hospital - Bonsucesso Federal Hospital -, located in the city of Rio de Janeiro, Brazil. This hospital belongs to the Network of Health Ministry Federal Hospitals of Rio de Janeiro and is a reference health unit for high risk pregnancies in the city of Rio de Janeiro, but also provides care for spontaneous demand from the population. Most people that come to this hospital for care do not have private health insurance and live in the surrounding geographic area, which includes numerous poor communities.

Data sources were the Live Birth Information System (Sinasc) from the State of Rio de Janeiro, covering January 2002 to December 2006 $(\mathrm{n}=1,137,831)$ and the hospital's databank $(\mathrm{n}=823)$, consisting of records from the neonatal intensive and intermediate care units, where all newborns weighing less than $1500 \mathrm{~g}$ are admitted. Initially, hospital and Sinasc databases were integrated using the probabilistic linkage technique (linkage 1). The study excluded twin newborns, those with birth weight less than $500 \mathrm{~g}$, records in which the birth weight information in the two databases diverged (taking the Sinasc base as the reference), and hospital records only (probable stillbirths), so that the final study sample included 782 records. Twins were excluded because record linkage of twin pregnancies is more complex, especially when they are of the same sex, because they share the same 
maternal and pregnancy information and birthday. We excluded newborns with birth weight less than $500 \mathrm{~g}$, as recommended by World Health Organization ${ }^{8}$ and to facilitate comparability, as many countries do not register these newborns. This base was then linked to the Mortality Information System (SIM) database of the State of Rio de Janeiro, for the years 2002 to $2007(n=721,361)$, which identified 225 deaths (linkage 2). Vital databases (Sinasc and SIM) were obtained from Rio de Janeiro State Department of Health and Civil Defense after the study's approval by the Institutional Review Board of Bonsucesso Federal Hospital.

Probabilistic database linkage used the RecLink III software. ${ }^{9}$ Multiple stepwise blocking strategies were used, and the number of steps varied between the two linkage processes (linkage $1=13$; linkage $2=$ 8). The key fields used for blocking were: Linkage 1: soundex codes for mother's first and last names, maternity hospital code, child's year of birth, and mother's first and last names. Linkage 2: soundex codes for mother's first and last names, child's year of birth, code of municipality of residence, and child's date of death. The items used for comparison were: Linkage 1: mother's full name, child's date of birth, birth weight, code of municipality of residence, and sex. Linkage 2: mother's full name and child's date of birth. Both linkage processes estimated linkage parameters in the first blocking step, and estimates were made with routines based on Expectation Maximization (EM) algorithms. 10 The resulting link scores varied from 10.7 to -7.7 (linkage 1) and from 28.3 to -11.3 (linkage 2). Each step included a clerical revision of all formed links, using rules defined in advance for attributing the pair's status (true or false).

Variables were gathered from the Sinasc database, and in cases of missing data they were complemented with data from the hospital base. The study variables were: maternal age in years: 10-19, 20-34, and 35 or older; maternal schooling (in years): 3 or less, 4-7, and 8 or more; mother's marital status: married or with a partner versus single; number of prenatal care visits: none, 1-3, 4-6, 7 or more; type of delivery: vaginal versus cesarean; birth weight (grams): 500-749, 750-999, 1000-1249, and 1250$1499 \mathrm{~g}$; 5-minute Apgar score: less than 7 versus 7 or higher; gestational age (weeks): 27 or less, 28-31, and 32 or more. For survival analysis, the last two birth weight intervals were grouped as 1000-1499 g. The outcome was death up to one year of age.

Data analyses were performed using the Stata 9.0 software. Results were presented as median values and other quartiles for continuous variables, while categorical variables were presented as proportions. The chi-square test was used to assess differences in the profile of newborns according to birth weight intervals. The death rates and respective $95 \%$ confidence intervals were calculated according to birth weight intervals and period of death (in days). We evaluated newborns' survival both overall and according to birth weight strata, maternal age, maternal schooling, mother's marital status, prenatal care, type of delivery, duration of pregnancy, and 5minute Apgar score. Survival was estimated as time (days) from birth until death. Censored cases were defined as infants that remained alive at the end of the observation period (one year). The Kaplan-Meier method was used to estimate the cumulative likelihood of survival during this period, stratified according to selected variables. Comparisons between curves used the log-rank test.

The association between maternal schooling and infant survival was evaluated using Cox's proportional risks models, adjusted for: prenatal care, birth weight, and gestational age at birth. Maternal age, although a known risk factor for infant mortality, was not included in our final model, since it presented an unexpected behavior in the bivariate analysis, with lower risk observed in the extreme age intervals (data not shown). This pattern strongly suggests the occurrence of a selective survival bias, indicating that its inclusion in the model might jeopardize interpretation of the results. Mothers in extreme age intervals may have suffered early fetal losses. The assumption of risk proportionality was evaluated using a statistical test based on the distribution of Schoenfeld residuals and graphic methods (log-log graphs and comparisons between estimates obtained by the Kaplan-Meier method and values predicted by Cox's proportional model). The analyses did not show any violation of proportionality assumptions.

\section{Results}

A total of 782 newborns were studied with a median birth weight of 1081 grams (inter-quartile interval: $845-1335 \mathrm{~g}$ ), with the following distribution: 127 (16.2\%) weighed 500 to $749 \mathrm{~g} ; 178(22.8 \%) 750$ to $999 \mathrm{~g} ; 187$ (23.9\%) 1000 to $1249 \mathrm{~g}$, and 290 (37.1\%) 1250 to $1499 \mathrm{~g}$. Three hundred and five newborns $(39 \%)$ weighed less than $1000 \mathrm{~g}$ at birth and were thus classified as extremely low birth weight.

Table 1 shows maternal, pregnancy, childbirth care and neonatal characteristics according to different birth weight intervals. No significant diffe- 
rences were observed between groups for maternal age, and marital status. The lowest birth weight categories showed higher proportions of women with less than four years of schooling $(p<0.001)$ and without prenatal care visits $(p<0.001)$. Cesarean delivery predominated in higher birth weight categories $(p<0.001)$. Meanwhile, gestational age increased significantly with birth weight $(p<0.001)$. Nine newborns were classified as having gestational age less than 22 weeks $(1.1 \%)$ and 30 with gesta- tional age from 37 to 41 weeks $(3.8 \%)$. There were proportionally lower five-minute Apgar scores in the lowest birth weight categories, especially 500 to 750 $\mathrm{g}(\mathrm{p}<0.001)$. For most variables, there were a few gaps in the data for all birth weight ranges. The only exception was Apgar at five minutes, for which there was a higher proportion of missing values for the following birth weight ranges: 500 to $749 \mathrm{~g}$ (7.1\%) and 1000 to $1249 \mathrm{~g}(5.9 \%)$.

Table 1

Characteristics of the mother, newborn, and pregnancy for very low birth weight infants according to birth weight intervals. Bonsucesso Federal Hospital, Rio de Janeiro, Brazil. January 2002 to December 2005.

\begin{tabular}{|c|c|c|c|c|c|c|c|c|c|c|c|}
\hline \multirow{3}{*}{ Characteristics } & \multicolumn{10}{|c|}{ Very low birth weight infants } & \multirow{3}{*}{$P$} \\
\hline & \multicolumn{2}{|c|}{$\begin{array}{c}500-749 \mathrm{~g} \\
(\mathrm{~N}=127)\end{array}$} & \multicolumn{2}{|c|}{$\begin{array}{c}750-999 \mathrm{~g} \\
(\mathrm{~N}=178)\end{array}$} & \multicolumn{2}{|c|}{$\begin{array}{c}1000-1249 \mathrm{~g} \\
(\mathrm{~N}=187)\end{array}$} & \multicolumn{2}{|c|}{$\begin{array}{c}1250-1499 \mathrm{~g} \\
(\mathrm{~N}=290)\end{array}$} & \multicolumn{2}{|c|}{$\begin{array}{l}\text { Total } \\
(\mathrm{N}=782)\end{array}$} & \\
\hline & $\bar{n}$ & $\%$ & $\mathrm{n}$ & $\%$ & $\mathrm{n}$ & $\%$ & $\mathrm{n}$ & $\%$ & $\mathrm{n}$ & $\overline{\%}$ & \\
\hline Maternal age (years) & & & & & & & & & & & 0.404 \\
\hline $10-19$ & 34 & 28.3 & 46 & 27.5 & 45 & 24.6 & 88 & 31.9 & 213 & 28.5 & \\
\hline $20-34$ & 71 & 59.2 & 91 & 54.5 & 115 & 62.8 & 149 & 54.0 & 426 & 57.1 & \\
\hline$\geq 35$ & 15 & 12.5 & 30 & 18.0 & 23 & 12.6 & 39 & 14.1 & 107 & 14.3 & \\
\hline Maternal schooling (years) & & & & & & & & & & & $<0.001$ \\
\hline$<4$ & 22 & 19.3 & 16 & 9.9 & 12 & 6.7 & 24 & 9.0 & 74 & 10.2 & \\
\hline $4-7$ & 44 & 38.6 & 55 & 34.2 & 61 & 33.9 & 120 & 44.9 & 280 & 38.8 & \\
\hline$\geq 8$ & 48 & 42.1 & 90 & 55.9 & 107 & 59.4 & 123 & 46.1 & 368 & 51.0 & \\
\hline Marital status & & & & & & & & & & & 0.245 \\
\hline Single & 105 & 84.0 & 157 & 90.2 & 154 & 83.2 & 245 & 86.0 & 661 & 86.0 & \\
\hline Married/With Partner & 20 & 6.0 & 17 & 9.8 & 31 & 16.8 & 40 & 14.0 & 108 & 14.0 & \\
\hline Prenatal care visits & & & & & & & & & & & $<0.001$ \\
\hline None & 45 & 39.1 & 53 & 32.7 & 38 & 22.1 & 45 & 17.3 & 181 & 25.5 & \\
\hline $1-3$ & 34 & 29.6 & 55 & 33.9 & 60 & 34.9 & 95 & 36.5 & 244 & 34.4 & \\
\hline $4-6$ & 28 & 24.3 & 38 & 23.5 & 62 & 36.0 & 93 & 35.8 & 221 & 31.2 & \\
\hline$\geq 7$ & 8 & 6.7 & 16 & 9.9 & 12 & 7.0 & 27 & 10.4 & 63 & 8.9 & \\
\hline Type of delivery & & & & & & & & & & & $<0.001$ \\
\hline Vaginal & 92 & 75.4 & 93 & 56.4 & 73 & 39.7 & 125 & 44.8 & 383 & 51.0 & \\
\hline Cesarean & 30 & 24.6 & 72 & 43.6 & 111 & 60.3 & 154 & 55.2 & 367 & 49.0 & \\
\hline Gestational age (weeks) & & & & & & & & & & & $<0.001$ \\
\hline$<22$ & 5 & 4.0 & 4 & 2.3 & 0 & 0.0 & 0 & 0.0 & 9 & 1.2 & \\
\hline $22-27$ & 86 & 68.8 & 61 & 35.1 & 19 & 10.3 & 11 & 3.9 & 177 & 23.1 & \\
\hline $28-31$ & 25 & 20.0 & 87 & 50.0 & 114 & 62.0 & 125 & 44.0 & 351 & 45.8 & \\
\hline $32-36$ & 6 & 4.8 & 18 & 10.3 & 40 & 21.7 & 136 & 47.9 & 200 & 26.0 & \\
\hline$>36$ & 3 & 2.4 & 4 & 2.3 & 11 & 6.0 & 12 & 4.2 & 30 & 3.9 & \\
\hline 5-min. Apgar & & & & & & & & & & & $<0.001$ \\
\hline$<7$ & 69 & 58.5 & 43 & 24.6 & 29 & 16.5 & 42 & 14.9 & 183 & 24.4 & \\
\hline$\geq 7$ & 49 & 41.5 & 132 & 75.4 & 147 & 83.5 & 240 & 85.1 & 568 & 75.6 & \\
\hline
\end{tabular}

Note: Excludes records with missing values, as follows: maternal age (36), maternal schooling (60), marital status (13), prenatal care visits (73), type of delivery (32), gestational age (15), Apgar (31). 
In this cohort of 782 very low birth weight infants, 225 died before completing one year of age $(28.8 \%, 95 \%$ CI $=25.6-32.1 \%)$. Neonatal mortality (death up to 28 incomplete days of life) was $20.5 \%$ $(95 \% \mathrm{CI}=17.7-23.5 \%)$, and early neonatal mortality (less than seven days of life) was $14.9 \%(95 \% \mathrm{CI}=$ 12.5-17.6\%). Post-neonatal mortality (between 28 and 364 complete days of life) was $8.3 \%(95 \% \mathrm{CI}=$ $6.5-10.5 \%)$. More than half of the deaths occurred before seven days of life $(117 / 225 ; 52 \%)$.

The mortality was high, especially in the 500 to 749 $\mathrm{g}$ category, in which $71.6 \%$ of the newborns died before reaching one year of age. In all periods studied, mortality was higher in the 500 to $749 \mathrm{~g}$ birth weight category. A significant decrease in mortality was observed proportionate to increased birth weight $(p<0.001)$ (Table 2$)$.

Table 2

Mortality rate according to birth weight intervals and age on death. Bonsucesso Federal Hospital, Rio de Janeiro, Brazil. January 2002 to December 2006

\begin{tabular}{|c|c|c|c|c|c|c|c|c|c|c|c|c|c|}
\hline \multirow{2}{*}{$\begin{array}{l}\text { Birth weight } \\
\text { intervals (g) }\end{array}$} & \multirow{2}{*}{$\begin{array}{l}\text { Total live } \\
\text { newborns }\end{array}$} & \multicolumn{3}{|c|}{0 to 6 days } & \multicolumn{3}{|c|}{7 to 28 days } & \multicolumn{3}{|c|}{29 to 364 days } & \multicolumn{3}{|c|}{ Total deaths } \\
\hline & & $\mathrm{n}$ & $\%$ & $95 \% \mathrm{Cl}$ & $\mathrm{n}$ & $\%$ & $95 \% \mathrm{Cl}$ & $n$ & $\%$ & $95 \% \mathrm{Cl}$ & $n$ & $\%$ & $95 \% \mathrm{Cl}$ \\
\hline $500-749$ & 127 & 60 & 47.2 & $38.3-56.3$ & 15 & 11.8 & $6.8-18.7$ & 16 & 12.6 & 7.4-19.6 & 91 & 71.6 & $63.0-79.3$ \\
\hline $750-999$ & 178 & 31 & 17.4 & $12.1-23.8$ & 13 & 7.3 & $3.9-12.2$ & 19 & 10.7 & $6.5-16.2$ & 63 & 35.4 & $28.3-42.9$ \\
\hline 1000-1499 & 477 & 26 & 5.4 & $3.6-7.9$ & 15 & 3.1 & $1.8-5.1$ & 30 & 6,3 & $4.3-8.9$ & 71 & 14.9 & $11.8-18.4$ \\
\hline Total & 782 & 117 & 14.9 & $12.5-17.6$ & 43 & 5.5 & $4.0-7.3$ & 65 & 8.3 & $6.5-10.5$ & 225 & 28.7 & $25.6-32.0$ \\
\hline
\end{tabular}

Figure 1 shows survival curves obtained using the Kaplan-Meier method and predefined variables. Lower survival was found among newborns with lower birth weight $(p<0.001)$ and lower gestationa age $(p<0.001)$ and among children of mothers with fewer years of schooling $(p<0.001)$. The number of prenatal care visits was not strongly associated with survival in these very low birth weight newborns.
Neither were there associations with the newborn's sex or the mother's marital status.

Newborns of mothers with less than 4 years of schooling had 2.4 times higher risk of death than those whose mothers had eight years of schooling or more, after adjusting the model for intermediate variables, although inclusion of the latter attenuated the strength of the association (Table 3 ). 


\section{Figure 1}

Survival curves (Kaplan-Meier estimates) in very low birth weight newborns according to birth weight, maternal schooling, gestational age, and prenatal care visits. Bonsucesso Federal Hospital, Rio de Janeiro, Brazil. January 2002 to December 2006.
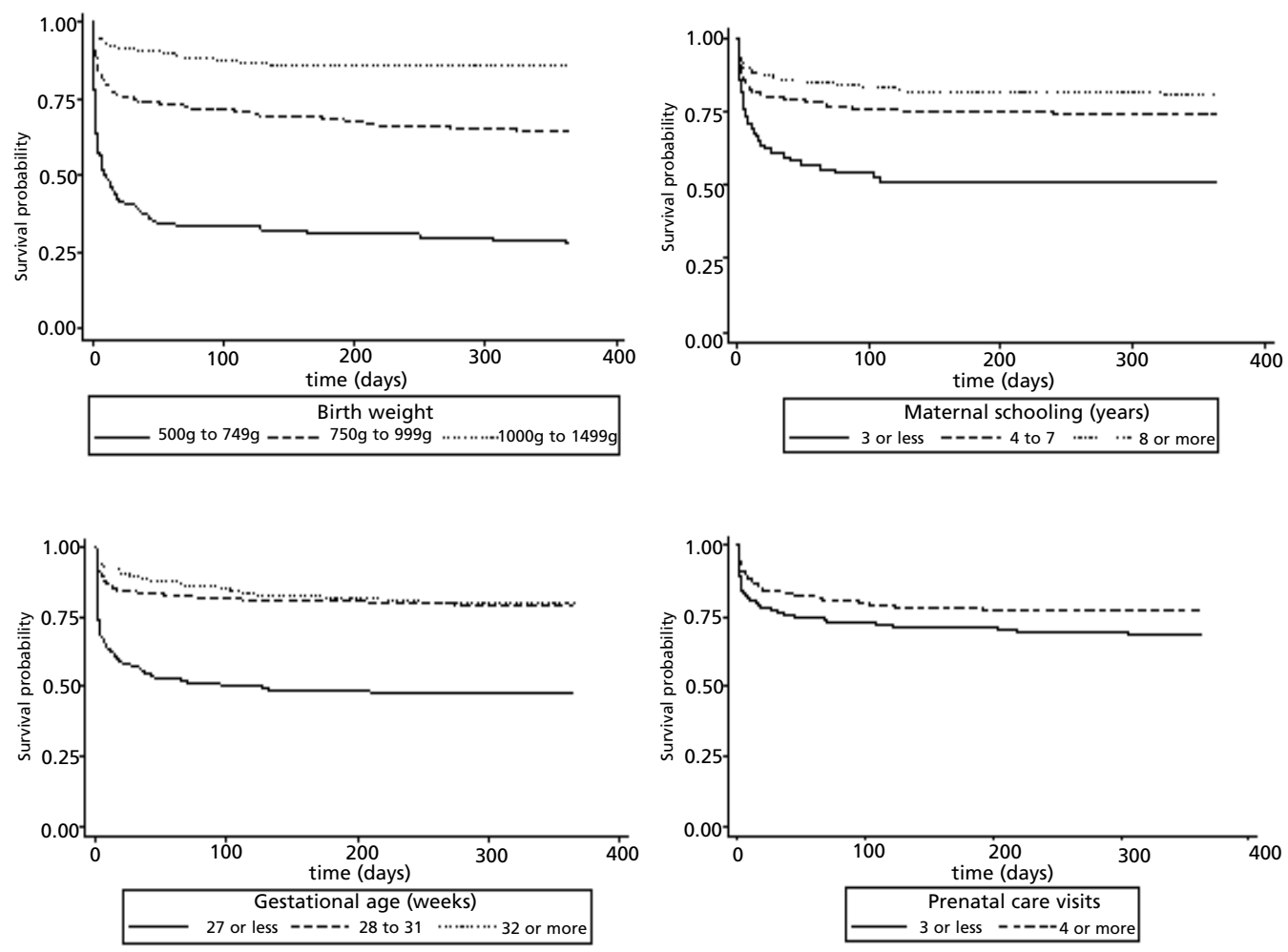

Log-rank test of survival function according to birth weight, maternal schooling and gestational age: $p<0.001$. Log-rank test of survival function according to prenatal care visits: $p<0.05$

Table 3

Crude and adjusted hazard ratios for the association between maternal schooling and infant mortality in very low birth weight newborns. Bonsucesso Federal Hospital, Rio de Janeiro, Brazil. January 2002 to December 2006.

\begin{tabular}{ccc}
\hline Maternal schooling (years) & Crude hazard ratio $(\mathbf{9 5} \% \mathrm{Cl})$ & Adjusted* hazard ratio $(\mathbf{9 5} \% \mathrm{Cl})$ \\
\hline$\geq 8$ & Reference & Reference \\
$<4$ & $3.29(2.12-4.84)$ & $2.40(1.56-3.64)$ \\
$4-7$ & $1.20(0.86-1.75)$ & $1.32(0.92-1.88)$
\end{tabular}

* Adjusted by prenatal care visits, birth weight, and gestational age. Number of observations $=648$. 


\section{Discussion}

According to the present study, infant mortality was high in very low birth weight newborns, especially among those with a birth weight between 500 and $749 \mathrm{~g}$. Another interesting finding was that even in a low-income population, low maternal schooling remained associated with increased risk of infant death, even after adjusting for mediating variables (birth weight categories, gestational age, and number of prenatal care visits).

Despite major progress in neonatal clinical practice in the 1990s, with improved survival rates for very low birth weight infants, mortality remains high, especially in extremely low birth weight neonates (below $1000 \mathrm{~g}$ ). ${ }^{11}$ According to a study by the Vermont Network in 39 institutions in the United States and Canada, which aimed to evaluate mortality in very low birth weight infants, there was a decrease in hospital mortality from $18.1 \%$ in 1991 to $14.4 \%$ in 1995 , but it was still as high as $14.8 \%$ in 1999, with little progress in the later period.12 However, a comparative study of two cohorts in Japan evaluating hospital mortality in extremely low birth weight infants showed significant progress in survival from 2000 to 2005.13 Results from the National Institute of Child Health and Human Development Neonatal Research Network indicate hospital mortality rates of around $15 \%$ for this birth weight category. 14 The United States vital statistics for 200415 show that one-fourth of newborns with birth weight less than $1500 \mathrm{~g}$ do not survive their first year of life. A study by the Southern Cone Neonatal Collaborative Group, which includes five South American countries, found a $26.7 \%$ mean hospital mortality rate for newborns weighing 500 to $1500 \mathrm{~g}$, ranging from $9.7 \%$ to $51.8 \%$ from one institution to another. 16

In Londrina, Brazil, a study 17 of health and mortality in very low birth weight newborns from 2002 to 2004 found a $32 \%$ hospital mortality rate, climbing to $87.5 \%$ in newborns weighing less than 750 g. A study conducted by the Brazilian Neonatal Research Network, including eight public tertiary maternity hospitals in three states, showed a $29 \%$ seven-day mortality rate in very low birth weight infants. ${ }^{18}$ Another study, in four public maternities in the city of Rio de Janeiro in 2001-2002, showed neonatal hospital mortality in very low birth weight newborns ranging from 10 to $37 \%$ according to hospital of birth. 19 Meanwhile in Fortaleza, in Northeast Brazil,20 researchers found a $47 \%$ hospital mortality rate in very low birth weight infants in a study carried out in 2002 and 2003. In the city of São
Paulo, a population-based study of a very low birth weight cohort showed higher neonatal mortality of $52.6 \%$, partially explained by variations in health care. ${ }^{21}$ There were important losses in this study, of roughly $30 \%$, perhaps leading to overestimation of the mortality rate. Pinheiro et al. 22 evaluated factors associated with survival in the first year of life in the city of Florianópolis (SC, Brazil), from 1999 to 2006, using Kaplan-Meier estimates. For the 500$999 \mathrm{~g}$ birth weight group, they found a survival probability of $32.8(95 \%$ CI $28.5 ; 37.2)$ and for the 1000 1499 g group, $82.0(79.1 ; 84.6)$, which is very similar to the results of the present study.

The present study showed a predominance of death in the early neonatal period, mainly in the lowest birth weight interval, which is consistent with the literature.1,4,16 In the city of Rio de Janeiro, survival of the whole birth cohort of 2005 was analyzed using actuarial life tables and KaplanMeier methods. The likelihood of death was higher in the first week $(0.0020$ in the first $24 \mathrm{~h}$ and 0.0045 from 1 to 6 days of life, compared to much lower values in the post-neonatal period). 23

Differences in the incidence of mortality between the above-mentioned studies and the findings of the present study reflect (albeit partially) methodological variations, particularly differences in the follow-up period and the use of different protocols for neonatal resuscitation at the limit of viability. The percentage of stillbirths should be considered in other studies of mortality in very low birth weight infants, since it has been observed that in hospitals with proportionately more stillbirths, neonatal survival is comparatively higher. 13 Even in developed countries, such as the UK, there is still not sufficient evidence to establish a cutoff point for birth weight and gestational age. ${ }^{11}$ In our cohort, 186 newborns (23.4\%) had a gestational age of less than 27 weeks and 305 (38.3\%) had birth weight below $1000 \mathrm{~g}$, which makes them more susceptible to adverse outcomes. Nevertheless, infant mortality in our study was nearly double that observed in 1999 by Jeffrey et al.,12 and Fanaroff et al., ${ }^{14}$ which could reflect both differences in maternal socioeconomic status and the quality of care provided.

The association between low socioeconomic status and low birth weight and infant mortality has been described in the international literature.2,7,24 Gortmaker and Wise 24 highlight substantial socioeconomic differences in infant mortality rates in the United States, even with the same level of care, indicating that when medical technology is equally available to everyone in a given geographic area, social and economic forces emerge as much more 
visible factors. Brazilian studies have also shown an association between low socioeconomic status and preterm birth, perinatal mortality, and infant mortality. 6,25,26 Carvalho et al. 17 observed a significant association between low income and hospital mortality, even after adjusting for other co-variables such as normal labor, Apgar score less than 3, gestational age, birth weight $750 \mathrm{~g}$ or less, lack of corticoid use, and mechanical ventilation.

As limitations of the present study, it is important to note that it was only possible to evaluate predictive factors that were present in the Sinasc database. Thus, important factors such as quality of prenatal care and type of treatment provided (for example, use of prenatal corticoids) were not considered, and neither was any risk score for severity of the newborns. The fact that the study was carried out at a single health unit also contributed to greater uniformity of health care. At Bonsucesso Federal Hospital, the treatment protocol for these newborns includes adequate equipment and professional teams with appropriately specialized training. The unit is equipped to manage high-risk pregnancies and is a referral center for this kind of care in its coverage area. The protocol includes corticoid use prior to delivery, early pulmonary surfactant, mechanical ventilation with less aggressive parameters, restricted use of blood products, minimal handling of infants, and humanization procedures. There was no change in the treatment protocol during the study period.

In relation to data quality, studies in Brazil have shown good reliability in live birth information systems. 27 As vital status was ascertained for the entire cohort using record linkage techniques, nonresponse to follow-up was not an issue in our study. Nevertheless, linkage errors could have caused outcome misclassification. Some pairs may be erroneously classified as true matches (false positive errors), whereas some true matches may be missed (false negative errors). In our study we performed an extensive clerical review in order to minimize false positive errors. False positive errors, even when nondifferential with regard to the exposure variable, bias both the risk difference and the risk ratio to the null, whereas non-differential false negative errors bias the risk difference rate but not the risk ratio. ${ }^{28} \mathrm{~A}$ previous study 29 using a similar linkage strategy found that linkage errors were non-differential, with satisfactory accuracy (sensitivity $87.6 \%$; specificity $99.6 \%$ ). Therefore, the mortality rate observed in the current study may be underestimated by approximately $10 \%$, while the study probably produced unbiased hazard ratio estimates.

Finally, we were not able to study the cohort's profile in relation to intrauterine growth and adequacy of weight for gestational age, since the gestational age variable is recorded in categories. Evans, in a cohort study, found an eight-fold increase in risk of death in newborns below the $3^{\text {rd }}$ percentile of weight for gestational age. 30

A strong point in this study was the fact that we applied a probabilistic linkage technique, which allowed longitudinal evaluation of infant mortality in a specific population of very low birth weight newborns. Lack of follow-up after hospital discharge is a limitation in many published studies of mortality, making it difficult to obtain a more precise evaluation of factors leading to death. This one-year follow-up allowed us to identify maternal schooling as an important independent predictive factor for mortality in very low birth weight newborns, even in a low-income population.

In conclusion, our results corroborate higher mortality among very low birth weight newborns, despite available therapeutic resources. Although the percentage of newborns in this weight category is relatively low in Brazil, their high mortality rate may increase the country's overall infant mortality rates, as observed elsewhere in the world and suggested in some Brazilian studies. Thus, efforts need to be made to avoid preterm births, specifically those involving birth weight below $1000 \mathrm{~g}$, and to improve care for very low birth weight infants, especially in the neonatal period. Special care should be provided for pregnant women and newborn infants of mothers with low schooling, given that they show a particularly high risk of early death.

\section{Acknowledgments}

This study received funding from the Rio de Janeiro State Research Foundation (FAPERJ- E26/100.691/2007; E-26/110.465/2007) and the Brazilian National Research Council (CNPq 473911/2009-4). Cláudia Medina Coeli and Katia Vergetti Bloch received research fellowship grants from CNPq. 


\section{References}

1. Mathews TJ, MacDorman MF. The challenge of infant mortality: have we reached a plateau? Public Health Rep. 2009; 124 (5): 670-81.

2. Kramer MS, Goulet L, Lydon J, Seguin L, McNamara H, Dassa C, Platt RW, Chen MF, Gauthier H, J Genest, Kahn S, Libman M, Rozen R, Masse A, Miner L, Asselin G, Benjamin A, Klein J, Koren G. Socio-economic disparities in preterm birth: causal pathways and mechanisms. Paediatr Perinat Epidemiol. 2001; 15 (Suppl. 2): 104-23.

3. Brasil. Ministério da Saúde. Departamento de Informática do SUS- DATASUS. [access on Sep 2 2010]. Available from: http://w3.datasus.gov.br/datasus/index.php

4. Goldani MZ, Barbieri MA, Rona RJ, Silva AAM, Bettiol $\mathrm{H}$. Increase in preterm and low-birth-weight rates over time and their impact on infant mortality in Southeast Brazil. J Biosoc Science. 2004; 36: 177-88.

5. Araújo RF, Tanaka ACD, Madi JM. Fatores de risco associados ao nascimento de recém-nascidos de muito baixo peso em uma população de baixa renda. Cad Saúde Pública. 2007; 23 (12): 2869-77.

6. Andrade CLT, Szwarcwald CL, Gama SGN, Leal MC. Desigualdades socioeconômicas do baixo peso ao nascer e da mortalidade perinatal no Município do Rio de Janeiro, 2001. Cad Saúde Pública. 2004; 20 (Suppl. 1): S44-S51.

7. Luo ZC, Wilkins R, Kramer MS, Fetal and Infant Health Study Group of the Canadian Perinatal Surveillance System. Effect of neighbourhood income and maternal education on birth outcomes: a population-based study. CMAJ. 2006; 174 (10): 1415-20.

8. WHO (World Health Organization). WHO LibraryCataloguing-in-Publication Data. Neonatal and perinatal mortality: country, regional and global estimates; 2006.

9. Camargo KR, Coeli CM. Reclink: aplicativo para o relacionamento de bases de dados, implementando no método probabilistic record linkage. Cad Saúde Pública. 2000; 16 (2): 439-47.

10. Junger WL. Estimação de parâmetros de relacionamento probabilístico de bancos de dados: uma aplicação do algoritmo EM para o RECLINK / Parameter estimation probabilistic record linkage: an application of the EM algorithm. Cad Saúde Coletiva. 2006; 14 (2): 225-32.

11. Field DJ, Dorling JS, Manktelow BN, Draper ES. Survival of extremely premature babies in a geographically defined population: prospective cohort study of 1994-9 compared with 2000-5. BMJ. 2008; 336: 1221-3.

12. Jeffrey D, Horbar JD, Gary J, Badger GJ, Carpenter H, Fanaroff AA, Kilpatrick S, LaCorte M, Phibbs R, Soll RF, Members of the Vermont Oxford Network. Trends in mortality and morbidity for very low birth weight infants, 1991-1999. Pediatrics. 2002; 110; 143-51.

13. Itabashi K, Takeshi H, Satoshi K, Kazuhiko K, Yasufumi I, Nakamura T, Fujimura M, Matsuo M. Mortality rates for extremely low birth weight infants born in Japan in 2005 . Pediatrics. 2009; 123 (2): 444-50.
14. Fanaroff AA, Stoll BJ, Wright LL, Carlo WA, Ehrenkranz RA, Stark AR, Bauer CR, Donovan EF, Korones SB, Laptook AR, Limões JA, Oh W, Papile LA, Shankaran S, Stevenson DK, Tyson JE, Poole WK, NICHD Neonatal Research Network. Trends in neonatal morbidity and mortality for very low birth weight infants. Am J Obstet Gynecol. 2007; 196: 147.e1-8.

15. Martin J A, Hsiang-Ching Kung, Mathews T J, Hoyert L, Strobino D M, Guyer B, Sutton S R. Annual Summary of Vital Statistics:2006. Pediatrics. 2008; 121; 4: 788-801.

16. Marshall G, Tapia JL, D'apremont I, Grandi C, Barros C, Alegria A, Standen J, Panizza R, L Roldan, Musante G, Bancalari A, Bambaren E, Lacarruba J, Hubner ME, Fabres J, Decaro M, Mariani G, Kurlat I, Gonzalez A, Grupo Colaborativo NEOCOSUR. A new score for predicting neonatal very low birth weight mortality risk in the NEOCOSUR South American Network. J Perinatol. 2005; 25 (9): 577-82.

17. Carvalho ABR, Brito ASJ, Matsuo T. Assistência à saúde e mortalidade de recém-nascidos de muito baixo peso. Rev Saúde Pública. 2007; 41 (6): 1003-12.

18. Almeida MFB, Guinsburg R, Martinez FE, Procianoy RS, Leone CR, Marba STM, Rugolo LMSS, Luz JH, Lopes JMA. Perinatal factors associated with early deaths of preterm infants born in Brazilian Network on Neonatal Research Centers. J Pediatr (Rio J.). 2008; 84 (4): 300-7.

19. Duarte JLB, Mendonça GAS. Comparação da mortalidade neonatal em recém-nascidos de muito baixo peso ao nascimento, em maternidades do Município do Rio de Janeiro, Brasil. Cad Saúde Pública. 2005; 21 (5): 1441-7.

20. Castro EC, Leite AJ. Hospital mortality rates of infants with birth weight less than or equal to $1500 \mathrm{~g}$ in the Northeast of Brazil. J Pediatr (Rio J.). 2007; 83 (1): 27-32.

21. Almeida MF, Alencar GP, Schoeps D, Novaes HMD, Campbell O, Rodrigues LC. Sobrevida e fatores de risco para mortalidade neonatal em uma coorte de nascidos vivos de muito baixo peso ao nascer, na Região Sul do Município de São Paulo, Brasil. Cad Saúde Pública. 2011; 27 (6): 1088-98.

22. Pinheiro CE, Peres MA, d'Orsi E. Aumento na sobrevida de crianças de grupos de peso baixo ao nascer em Santa Catarina. Rev Saúde Pública. 2010; 44 (5): 776-84.

23. Noronha GA, Torres TG, Kale PL. Análise da sobrevida infantil segundo características maternas, da gestação, do parto e do recém-nascido na coorte de nascimento de 2005 no Município do Rio de Janeiro-RJ, Brasil. Epidemiol Serv Saúde. 2012; 21 (3): 419-30.

24. Gortmarker SL, Wise PH. The first injustice: socioeconomic disparities, health services technology, and infant mortality. Annu Rev Sociol. 1997; 23: 147-70.

25. Silveira MF, Victora CG, Barros AJD, Santos IS, Matijasevich A, Barros FC. Determinants of preterm birth: Pelotas, Rio Grande do Sul State, Brazil, 2004 birth cohort. Cad Saúde Pública. 2010; 26 (1): 185-94. 
26. Fonseca SC, Coutinho, ESF. Pesquisa sobre mortalidade perinatal no Brasil: revisão da metodologia e dos resultados. Cad Saúde Pública. 2004; 20 (1): 7-19.

27. Theme Filha MM, Gama SGN, Cunha CB, Leal MC. Confiabilidade do Sistema de Informações sobre Nascidos Vivos Hospitalares no município do Rio de Janeiro, 19992001. Cad Saúde Pública. 2004; 20 (1): 583-91.

28. Blakely T, Salmond C. Probabilistic record linkage and a method to calculate the positive predictive value. Int $\mathrm{J}$ Epidemiol. 2002; 31: 1246-52.
29. Fonseca MGP, Coeli CM, Lucena FFA, Veloso VG, Carvalho MS. Accuracy of a probabilistic record linkage strategy applied to identify deaths among cases reported to the Brazilian AIDS surveillance database. Cad Saúde Pública. 2010; 26: 1431-8.

30. Evans N, Hutchinson J, Simpson J M, Donohue D, Darlow B, Henderson-Smart D. Prenatal predictors of mortality in very preterm infants cared for in the Australian and New Zealand Neonatal Network. Arch Dis Child Fetal Neonatal. 2007; 92: 34-40.

Recebido em 14 de novembro de 2012

Versão final apresentada em 20 de maio de 2013

Aprovado em 20 de junho de 2013 